\title{
Endogenous Signaling by Omega-3 Docosahexaenoic Acid-derived Mediators Sustains Homeostatic Synaptic and Circuitry Integrity
}

\author{
Nicolas G. Bazan • Alberto E. Musto • Eric J. Knott
}

Received: 22 August 2011 / Accepted: 22 August 2011 /Published online: 15 September 2011

(C) The Author(s) 2011. This article is published with open access at Springerlink.com

\begin{abstract}
The harmony and function of the complex brain circuits and synapses are sustained mainly by excitatory and inhibitory neurotransmission, neurotrophins, gene regulation, and factors, many of which are incompletely understood. A common feature of brain circuit components, such as dendrites, synaptic membranes, and other membranes of the nervous system, is that they are richly endowed in docosahexaenoic acid (DHA), the main member of the omega-3 essential fatty acid family. DHA is avidly retained and concentrated in the nervous system and known to play a role in neuroprotection, memory, and vision. Only recently has it become apparent why the surprisingly rapid increases in free (unesterified) DHA pool size take place at the onset of seizures or brain injury. This phenomenon began to be clarified by the discovery of neuroprotectin D1 (NPD1), the first-uncovered bioactive docosanoid formed from free DHA through 15lipoxygenase-1 (15-LOX-1). NPD1 synthesis includes, as agonists, oxidative stress and neurotrophins. The evolving concept is that DHA-derived docosanoids set in motion endogenous signaling to sustain homeostatic synaptic and circuit integrity. NPD1 is anti-inflammatory, displays inflammatory resolving activities, and induces cell survival, which is in contrast to the pro-inflammatory actions of the many of omega- 6 fatty acid family members. We highlight here studies relevant to the ability of DHA to
\end{abstract}

N. G. Bazan $(\bowtie) \cdot$ A. E. Musto $•$ E. J. Knott

Neuroscience Center of Excellence,

Louisiana State University Health Sciences Center,

2020 Gravier Street, Suite D,

New Orleans, LA 70112, USA

e-mail: nbazan@1suhsc.edu sustain neuronal function and protect synapses and circuits in the context of DHA signalolipidomics. DHA signalolipidomics comprises the integration of the cellular/ tissue mechanism of DHA uptake, its distribution among cellular compartments, the organization and function of membrane domains containing DHA phospholipids, and the precise cellular and molecular events revealed by the uncovering of signaling pathways regulated by docosanoids endowed with prohomeostatic and cell survival bioactivity. Therefore, this approach offers emerging targets for prevention, pharmaceutical intervention, and clinical translation involving DHA-mediated signaling.

Keywords Epilepsy · Neuroprotectin D1 · Photoreceptors · Retinal pigment epithelial cells $\cdot$ Liver

$\begin{array}{ll}\text { Abbreviations } \\ \text { 15-LOX-1 } & \text { 15-lipoxygenase-1 } \\ \text { A } \beta & \text { Amyloid-beta } \\ \text { ALA } & \text { Alpha-linolenic acid } \\ \text { AD } & \text { Alzheimer's disease } \\ \text { AA } & \text { Arachidonic acid } \\ \text { BAPP } & \text { Beta-amyloid precursor protein } \\ \text { CNS } & \text { Central nervous system } \\ \text { DHA } & \text { Docosahexaenoic acid } \\ \text { EAAC1 } & \text { Excitatory aminoacid transporter 1 } \\ \text { FA } & \text { Fatty acid } \\ \text { GABA } & \text { Gamma-aminobutyric acid } \\ \text { GLAST } & \text { Glutamate aspartate transporter } \\ \text { GLT1 } & \text { Glutamate transporter 1 } \\ \text { LA } & \text { Linolenic acid } \\ \text { NPD1 } & \text { Neuroprotectin D1 } \\ \text { PLA } 2 & \text { Phospholipase } \text { A }_{2} \\ \text { PP2A } & \text { Protein phosphatase 2A } \\ \text { RPE } & \text { Retinal pigment epithelium }\end{array}$




\section{Introduction}

The availability of omega-3 essential fatty acids (FAs) in the Western diet has dramatically decreased during the last several decades. The health consequences of this shift in the diet on brain diseases are underestimated. The global burden of alcohol and drug dependence, depression, dementia, and several other mental and neurological diseases is greater than that of cancer and cardiovascular disease [1]. Because docosahexaenoic acid (DHA; 22:6, n-3), a major member of the omega-3 FA family, accumulates and is avidly retained in central nervous system (CNS) membranes (mainly synapses, dendrites, and photoreceptors), the impact of this fatty acid on synaptic function and circuitry integrity is incompletely understood.

Here, we provide an overview of the evolving knowledge on cellular and molecular mechanisms of DHA action. DHA plays a major role in neuroprotection, memory, and vision. Therefore, to unravel its significance, DHA signalolipidomics [2] represents a comprehensive approach that includes the cellular/tissue organization of DHA uptake, its distribution among cellular compartments, the organization and function of membrane domains rich in DHA-containing phospholipids, and molecular pathways regulated by DHA-derived bioactive lipids (docosanoids), which include neuroprotectin D1 (NPD1), a novel DHA-derived stereoselective mediator [2]. One aspect relevant to nutrition and addiction we discuss here is that when hippocampal circuitry is challenged with successive subconvulsive electrical stimulations to generate an epileptic state, it is restored toward physiological conditions by NPD1 [3]. The implication is that NPD1 bioactivity in seizures or the initial stages of neurodegenerative diseases offers an innovative approach involving DHA signaling and opens a new set of questions relevant to the modulation of homeostatic synaptic and circuit integrity.

\section{DHA is Essential in Human Nervous System Development and Function}

DHA supply is required during pre- and post-natal development to build functionally critical brain circuits. Synaptogenesis, dentrite formation, photoreceptor membrane biogenesis, and biogenesis of other neural membranes take place during early post-natal development. The phospholipids of these membranes are richly endowed with DHA. Linolenic acid (LA; 18:3, n-3), another essential fatty acid, leads to DHA synthesis through a series of elongation and desaturation steps. In humans, dietary supplies of LA are not able to cope with the needs of the nervous system. In fact, dietary DHA itself is needed to fulfill the developmental demands of the nervous system [4]. A shortage of DHA during the pre- and post-natal developmental stage usually results from a dietary shortage of maternally provided DHA in the placenta and breast milk [1]. DHA supply to the nervous system is required throughout life in much smaller proportions because of the tenacity through which this fatty acid is retained. In pathological conditions, DHA loss due to peroxidation may enhance its requirements. For example, a substantial loss of DHA has been observed in Alzheimer's disease (AD) brains [5].

The omega- 6 fatty acid family is also essential and gives rise to arachidonic acid (AA; 20:4, n-6), which in turn is widely distributed in tissues and serves as the precursor of eicosanoids. Both AA and DHA compete for several of the enzymes that catalyze elongation and desaturation. DHA, unlike AA, is enriched in the nervous system. Both families of essential fatty acids are ultimately required from the diet.

\section{DHA is Supplied by the Liver for Synaptogenesis and Neural Membrane Biogenesis}

Dietary linolenic acid is elongated and desaturated into DHA in the liver. The liver takes up dietary DHA, uses it for the biosynthesis of phospholipids, and then distributes these lipids to tissues in the CNS. This liver-to-CNS route is upregulated during pre- and post-natal development, when neural cells and their circuits are built. Strikingly, labeled omega-3s injected into developing rodents first appeared in the liver and decreased subsequently in a time-dependent manner, whereas labeled DHA evolved and appeared esterified to phospholipids and triglycerides; furthermore, rats intravenously infused with labeled alpha-linolenic acid (ALA) for $2 \mathrm{~h}$ confirmed the ability of the liver to supply DHA to the brain and showed the appearance of esterified DHA in a sigmoidal time-dependent manner [6-8]. This was concurrent with the decrease of labeled ALA in plasma. These studies allowed for mathematical modeling of liver synthesis and secretion rates of DHA from plasma ALA. By using positron emission tomography scans together with radio-tracer studies, relative incorporation rates have been estimated for humans and experimental animals. In healthy 15-week-old rats, liver conversion of ALA to DHA surpassed the brain consumption rate 30fold [7, 9, 10]. Similar studies in humans confirmed the liver's ability to provide physiologically adequate amounts of DHA when ALA was present in the diet [10]. The hepatic conversion of ALA to DHA in healthy individuals is sufficient to meet the demands of DHA in the brain and retina $[8,11]$. The relative significance of LA to fulfill the 
demands of DHA from the nervous tissue has recently been put into perspective [4].

The hypothesis that the brain directs DHA release from the liver, likely as DHA phospholipids in lipoproteins [11, 12] and in the form of brain/retina-to-liver signaling, remains to be tested. Since DHA is so critical to brain and retina function, and since its availability depends on the diet, conservation mechanisms assure its supply and retention. In the retina and intercellular loop, DHA retention is assured during the daily, massive exit of DHA phospholipids from photoreceptor tips during photoreceptor cell renewal [2, 13, 14]. A large supply of DHA accumulates in the liver during the biogenesis of membranes in the nervous system, and signals more than likely evoke the release of this fatty acid from the liver when necessary, such as during DHA loss in neurodegenerative diseases [11]. Moreover, nutritional studies addressing DHA supply to the nervous system must take into consideration the period when the study is performed and its duration. During post-natal development, rapid DHA uptake occurs; however, once DHA is taken up by nervous tissue, smaller amounts are required.

\section{Neuroprotectin D1 and the Free Pool of Docosahexaenoic Acid}

The brain, photoreceptors, and retinal pigment epithelial (RPE) cells display an undetectable quantity of unesterified (free) DHA (as is the case with unesterified arachidonic acid) under basal, non-stimulated conditions [15-17]. This indicates that the pool size of unesterified DHA is tightly controlled by phospholipase $\mathrm{A}_{2}\left(\mathrm{PLA}_{2}\right)$, reacylation, and by peroxidation (under some conditions). Free DHA, incorporated into membrane phospholipids, first becomes the substrate of docosahexaenoyl-coenzyme A synthesis for channeling through acyltransferases, which incorporate this FA into phospholipids [18].

RPE cells modulate the uptake, conservation, and delivery of DHA to photoreceptors [19]. Cells actively modulate the free DHA pool size in vitro when DHA is added in micromolar concentrations. The selectivity of the effects studied under these conditions, as well as the nonspecific response and potential toxicity, need to be assessed. RPE cells use a specific DHA-phospholipid pool as a precursor for NPD1 synthesis, and the selective oxygenation of DHA by 15-lipoxygenase-1 (15-LOX-1) leads to NPD1 synthesis [20]. Oxidative stress, neurotrophins, ischemia/reperfusion, amyloid-beta (A $\beta) 42$ and betaamyloid precursor protein ( $\beta$ APP) are all inducers of NPD1 synthesis, but the molecular details of this induction are not completely understood. Figure 1 outlines the uptake of DHA from the bloodstream and its distribution in astrocytes and neurons. Several of the routes depicted are still hypothetical.

NPD1 bioactivity triggers homeostatic/pro-survival signaling in response to cellular and systemic insults $[5,13,21]$. Specifically, NPD1 upregulates anti-apoptotic proteins (Bcl-2 and $\mathrm{Bcl}-\mathrm{xL}$ ) and downregulates pro-apoptotic proteins (Bax and $\mathrm{Bad}$ ) in response to cellular oxidative stress and cytokine activation, leading to an overall pro-survival transcriptome [5, 13, 21, 22]. NPD1 also provides a specific mechanism to understand DHA-mediated modulation of neuroinflammation and neuroprotection. Moreover, NPD1 elicits neuroprotection in brain ischemia/reperfusion and in oxidativestressed retinal cells [21-23], and it inhibits retinal ganglion cell death [24]. NPD1 is also protective in kidney ischemia/ reperfusion [25] and regulates adiponectin [26]. DNA microarray profiling shows downregulation of proinflammatory genes as well as of pro-apoptotic genes of the Bcl-2 gene family [5]; thus, NPD1 is a stereo-specific mediator that executes protective bioactivity of DHA in the CNS. Deficiency of NPD1 and of the enzyme involved in its formation, 15-LOX-1, has been observed in AD brain [5]. Also, NPD1 further influences $\beta$ APP processing and decreases $A \beta 42$ release [5]. DHA, the precursor of NPD1, elicits an $A \beta 42$-lowering effect both in vitro and in vivo [27-29]. In addition, free radical-mediated DHA peroxidation products accumulate during ischemia and neurodegeneration. In turn, these oxidation products may form protein adducts and other cytotoxic molecules that promote further free radical injury [30-32].

\section{DHA-NPD1 Significance in Epileptogenesis}

Epileptogenesis affects circuits and neurotransmissions, leading to aberrant connections and spontaneous seizures. Seizures induce enhancements in free DHA at the synapses [33]. The below subsections summarize studies undertaken to understand the significance of DHA and NPD1 in a model of epileptogenesis.

Seizures Evoke Neuroprotectin D1 Synthesis in the Hippocampus Systemic administration of DHA enhances NPD1 synthesis at the onset of generalized seizures in the hippocampus [3], the region most affected by limbic seizures and critical to controlling seizure propagation. NPD1 synthesis is initiated by the release of DHA through PLA $_{2}$ followed by $15-L O X-1[20,34]$. Seizureinduced early activation of NPD1 synthesis suggests induction of endogenous mechanism/s that might be involved in control of seizure development and reduction or prevention of brain damage. Also, small increases in NPD1 occur in the ipsilateral frontal cortex and brain stem, indicating neural circuits that are 
Fig. 1 Movement of docosahexaenoic acid (DHA) (22:6) through the neurovascular unit and its disposition within neurons and astrocytes. 22:6-Phospholipids (22:6-PLs) are taken up by endothelial cells from the circulation and transferred to astrocytes within the central nervous system; from there, 22:6 is incorporated into astrocytes or transferred to neurons. 22:6 is also available for conversion to neuroprotectin D1 (NPD1) upon inductive signals. After packaging in the endoplasmic reticulum and the Golgi apparatus, 22:6 is also transported to the synaptic terminal to become incorporated into synaptic elements. Arrows represent possible routes. Molecular characterization of transporter(s) and receptors remains to be done. Reprinted, with permission, from the Annual Review of Nutrition, Volume 31 (C) 2011 by Annual Reviews www.annualreviews.org

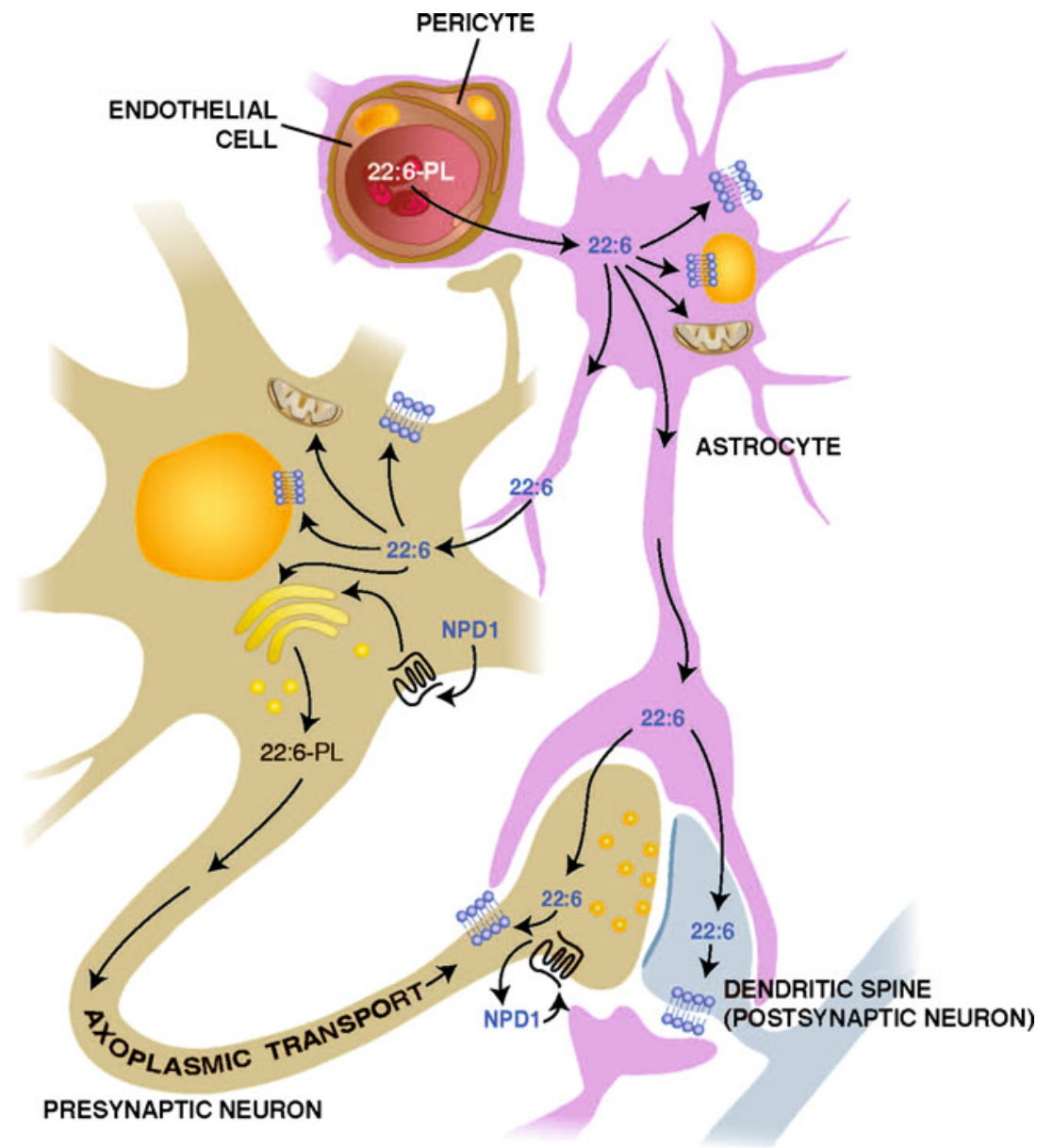

activated during the progression from partial to generalized seizures [3].

Neuroprotectin D1 Attenuates Hippocampal Epileptiform Activity and Progression of Motor Seizures In a model of temporal lobe epilepsy [3, 35, 36], NPD1 or its precursor, DHA, reduced seizure severity and duration of epileptiform activity in the hippocampus [3]. NPD1 alone limited progression of severe motor seizures and modified seizure-evoked morphology, as represented by spikes followed by small amplitude polyspikes [3]. NPD1 also modulated different phases of the epileptiform discharges $[3,35]$, suggesting involvement of a homeostatic excitatory-inhibitory mechanism in hippocampal circuitry. Since DHA is actively converted into NPD1 as a consequence of seizures, this lipid mediator may be responsible for DHA bioactivity in experimental epilepsy [37].

Neuroprotectin D1 Attenuates Hippocampal Hyperexcitability and Seizure Spread NPD1 attenuates hippocampal hyperexcitability at least 1 week after kindling acquisition [3], revealing its effective modification of kindling progression through an excitability mechanism related with the spread of seizures. Thus, NPD1 or DHA may control the spread of seizures through a mechanism more closely related with epileptogenesis [3] than ictiogenesis [38]. Glutamate transporter 1 (GLT1), glutamate aspartate transporter (GLAST), and excitatory amino acid transporter 1 (EAAC1) are modulated by DHA [39], suggesting that this fatty acid regulates glutamate availability at the synapses through glutamate transporters. Impaired glutamate uptake occurs in experimental models of epilepsy and epileptic patients; as a consequence, glutamate is elevated during induction and propagation of seizures [40]. On the other hand, DHA regulates gammaaminobutyric acid (GABA) receptor subunits [41]; as a result, the imbalance of the excitatory-inhibitory mechanisms during seizures may be restored by NPD1. Also, NPD1 may attenuate hippocampal hyperexcitability by limiting cellular inflammatory responses in the brain.

In addition, both astrocytes [42] and cytokines are major participants in epileptogenesis [43, 44]. Cytokine-mediated activation of pro-inflammatory signaling is downregulated by NPD1 [22], which is consistent with other models of brain damage/neuroinflammation [21] and retinal models of oxidative stress $[5,13,22,45]$. 


\section{Neuroprotectin D1 Induces Cell Survival by Targeting Pre-mitochondrial Steps of the Apoptotic Cascade}

In addition to the above-described events, NPD1 induces cell survival. This is mediated by actions on Bcl-2 proteins at pre-mitochondrial steps of the apoptotic cascade. The serine/theonin protein phosphatase, protein phosphatase $2 \mathrm{~A}$ (PP2A), dephosphorylates Bcl-2 family proteins [46-48]. PP2A has catalytic (C-subunit), structural (A-subunit), and regulatory (B-subunit) subunits. The A and B subunits are ubiquitously expressed and evolutionarily conserved. The B subunit targets the catalytic complex (AC) to microtubules, the nucleus, or the cytoplasm $[49,50]$. PP2A is the main phosphatase that dephosphorylates Bad [48], resulting in apoptosis. The catalytic subunit of PP2A alone is sufficient to dephosphorylate Bcl-2 [50] and Bax, and thus can help reduce or prevent cell death [51].

NPD1 induces dephosphorylation of S62Bcl-xL, and studies regarding this uncovered a mechanism to control the expression of anti- and pro-apoptotic factors in response to oxidative stress [51]. Bcl-xL phosphorylation in RPE cells is induced by oxidative stress, and NPD1 enhances PP2A activity, in turn downregulating oxidative stress-induced phosphorylation of the anti-apoptotic protein Bcl-xL. Therefore, NPD1 is a regulator of the $\mathrm{PP} 2 \mathrm{~A} / \mathrm{C} / \mathrm{Bcl}-\mathrm{xL}$ interaction, which suggests a stimulus-specific response in NPD1dependent phosphorylation of Bcl-xL. NPD1 modulates the activation of this $\mathrm{Bcl}-2$ family member by modifying the phosphorylation status in a PP2A-dependent manner and also by facilitating the interaction of its counterpart pro-apoptotic protein Bax, pointing to a highly coordinated, NPD1-mediated regulation of cell survival in response to oxidative stress [52].

\section{Outlook}

The study of DHA signalolipidomics will continue to unravel the significance of lipids containing DHA in brain function. Membrane lipids in synapses and neuronal circuits are richly endowed with DHA, and it is therefore of the utmost importance to investigate the effectiveness of the dietary supply of this and other fatty acids, as well as the potential effects of their supplementation, on brain function. Due to the identification of bioactive DHA mediators, mainly NPD1, we can now begin resolving the fundamental question of how DHA contributes to brain function. Recently, DHA signalolipidomics and nutrition were reviewed in regards to function and diseases of the nervous system [2]. One example of how the study of DHA signalolipidomics can be applied is in studying the involvement of the dopaminergic system in addiction. Do deficits in dietary availability of omega- 3 essential fatty acids enhance addictive behavior/s? Does nutrition selectively modify dopaminergic neurotransmission? Does nutrition also modify other neurotransmitter systems? Are there interactions between omega-3 fatty acids and endocannabinoids? What are the consequences of nutritional DHA deficits? Are there alternative events, since key nervous system functions are supported by redundant mechanisms? Will dietary supplementation be sufficient? These are just a few questions DHA signalolipidomics can address in a myriad of evolving issues.

Acknowledgments This work was supported by the National Institutes of Health, National Eye Institute (R01 EY005121), National Institute for Neurological Disorders and Stroke (R01 NS046741), and National Center for Research Resources (P20 RR016816) (N.G.B.).

Open Access This article is distributed under the terms of the Creative Commons Attribution Noncommercial License which permits any noncommercial use, distribution, and reproduction in any medium, provided the original author(s) and source are credited.

\section{References}

1. Collins PY, Patel V, Joestl SS, March D, Insel TR, Daar AS et al (2011) Grand challenges in global mental health. Nature 475:27-30

2. Bazan NG, Molina MF, Gordon WC (2011) Docosahexaenoic acid signalolipidomics in nutrition: significance in aging, neuroinflammation, macular degeneration, Alzheimer's, and other neurodegenerative diseases. Annu Rev Nutr 31:321-351

3. Musto AE, Gjorstrup P, Bazan NG (2011) The omega-3 fatty acidderived neuroprotectin D1 limits hippocampal hyperexcitability and seizure susceptibility in kindling epileptogenesis. Epilepsia. (in press)

4. Marcheselli VL, Mukherjee PK, Arita M, Hong S, Antony R, Sheets K, Winkler JW, Petasis NA, Serhan CN, Bazan NG (2010) Neuroprotectin D1/protectin D1 stereoselective and specific binding with human retinal pigment epithelial cells and neutrophils. Prostaglandins Leukot Essent Fatty Acids 82:27-34

5. Lukiw WJ, Cui J, Marcheselli VL, Bodker M, Botkjaer A, Gotlinger K, Serhan CN, Bazan NG (2005) A role for docosahexaenoic acid-derived neuroprotectin D1 in neural cell survival and Alzheimer disease. J Clin Invest 115:2774-2783

6. Gao F, Kiesewetter D, Chang L, Ma K, Bell JM et al (2009) Whole-body synthesis-secretion rates of long-chain n-3 PUFAs from circulating unesterified alpha-linolenic acid in unanesthetized rats. J Lipid Res 50:749-758

7. Rapoport SI, Igarashi M (2009) Can the rat liver maintain normal brain DHA metabolism in the absence of dietary DHA? Prostaglandins Leukot Essent Fatty Acids 81:119-123

8. Rapoport SI, Igarashi M, Gao F (2010) Quantitative contributions of diet and liver synthesis to docosahexaenoic acid homeostasis. Prostaglandins Leukot Essent Fatty Acids 82:273-276

9. Giovacchini G, Chang MC, Channing MA, Toczek M, Mason A et al (2002) Brain incorporation of [11C]arachidonic acid in young healthy humans measured with positron emission tomography. J Cereb Blood Flow Metab 22:1453-1462

10. Rapoport SI, Rao JS, Igarashi M (2007) Brain metabolism of nutritionally essential polyunsaturated fatty acids depends on both the diet and the liver. Prostaglandins Leukot Essent Fatty Acids 77:251-261

11. Scott BL, Bazan NG (1989) Membrane docosahexaenoate is supplied to the developing brain and retina by the liver. Proc Natl Acad Sci U S A 86:2903-2907 
12. Bazan NG, Rodriguez de Turco EB (1995) Alterations in plasma lipoproteins and DHA transport in progressive rod-cone degeneration (pred). In: Kato S, Osborne NN, Tamai M (eds) Retinal degeneration and regeneration, Proceedings of an International Symposium in Kanazawa, Japan. Kugler Publications, New York, pp 89-97

13. Bazan NG (2007) Homeostatic regulation of photoreceptor cell integrity: significance of the potent mediator neuroprotectin D1 biosynthesized from docosahexaenoic acid: the Proctor Lecture. Invest Ophthalmol Vis Sci 48:4866-4881

14. Gordon WC, Bazan NG (1990) Docosahexaenoic acid utilization during rod photoreceptor cell renewal. J Neurosci 10:2190-2202

15. Bazan NG (2003) Synaptic lipid signaling: significance of polyunsaturated fatty acids and platelet-activating factor. J Lipid Res 44:2221-2233

16. Horrocks LA, Farooqui AA (1994) NMDA receptor-stimulated release of arachidonic acid: mechanisms for the Bazan effect. In: Municio AM, Miras-Portugal MT (eds) Cell signal transduction, second messengers, and protein phosphorylation in health and disease. Plenum, New York, pp 113-128

17. Sun GY, Xu J, Jensen MD, Simonyi A (2004) Phospholipase A2 in the central nervous system: implications for neurodegenerative diseases. J Lipid Res 45:205-213

18. Reddy TS, Bazan NG (1985) Synthesis of arachidonoyl coenzyme A and docosahexaenoyl coenzyme A in synaptic plasma membranes of cerebrum and microsomes of cerebrum, cerebellum, and brain stem of rat brain. J Neurosci Res 13:381-390

19. Bazan NG, Birkle DL, Reddy TS (1985) Biochemical and nutritional aspects of the metabolism of polyunsaturated fatty acids and phospholipids in experimental models of retinal degeneration. In: LaVail MM, Hollyfield JG, Anderson RE (eds) Retinal degeneration: experimental and clinical studies. Liss, New York, pp 159-187

20. Calandria JM, Marcheselli VL, Mukherjee PK, Uddin J, Winkler JW, Petasis NA, Bazan NG (2009) Selective survival rescue in 15lipoxygenase-1-deficient retinal pigment epithelial cells by the novel docosahexaenoic acid-derived mediator, neuroprotectin D1. J Biol Chem 284:17877-17882

21. Marcheselli VL, Hong S, Lukiw WJ, Tian XH, Gronert K, Musto A, Hardy M, Gimenez JM, Chiang N, Serhan CN, Bazan NG (2003) Novel docosanoids inhibit brain ischemia-reperfusionmediated leukocyte infiltration and pro-inflammatory gene expression. J Biol Chem 278:43807-43817

22. Mukherjee PK, Marcheselli VL, Serhan CN, Bazan NG (2004) Neuroprotectin D1: a docosahexaenoic acid-derived docosatriene protects human retinal pigment epithelial cells from oxidative stress. Proc Natl Acad Sci U S A 101:84918496

23. Mukherjee PK, Marcheselli VL, de Rivero Vaccari JC, Gordon WC, Jackson FE, Bazan NG (2007) Photoreceptor outer segment phagocytosis attenuates oxidative stress-induced apoptosis with concomitant neuroprotectin D1 synthesis. Proc Natl Acad Sci U S A 104:13158-13163

24. Qin Q, Patil KA, Gronert K, Sharma SC (2008) Neuroprotectin D1 inhibits retinal ganglion cell death following axotomy. Prostaglandins Leukot Essent Fatty Acids 79:201-207

25. Hassan IR, Gronert K (2009) Acute changes in dietary omega-3 and omega- 6 polyunsaturated fatty acids have a pronounced impact on survival following ischemic renal injury and formation of renoprotective docosahexaenoic acid-derived protectin D1. J Immunol 182:3223-3232

26. González-Périz A, Horrillo R, Ferré N, Gronert K, Dong B et al (2009) Obesity-induced insulin resistance and hepatic steatosis are alleviated by omega-3 fatty acids: a role for resolvins and protectins. FASEB J 23:1946-1957
27. Lim GP, Calon F, Morihara T, Yang F, Teter B et al (2005) A diet enriched with the omega-3 fatty acid docosahexaenoic acid reduces amyloid burden in an aged Alzheimer mouse model. J Neurosci 25:3032-3040

28. Oksman M, Iivonen H, Hogyes E, Amtul Z, Penke B et al (2006) Impact of different saturated fatty acid, polyunsaturated fatty acid and cholesterol containing diets on beta-amyloid accumulation in APP/PS1 transgenic mice. Neurobiol Dis 23:563-572

29. Sahlin C, Pettersson FE, Nilsson LN, Lannfelt L, Johansson AS (2007) Docosahexaenoic acid stimulates non-amyloidogenic APP processing resulting in reduced Abeta levels in cellular models of Alzheimer's disease. Eur J Neurosci 26:882-889

30. Galasko D, Montine TJ (2010) Biomarkers of oxidative damage and inflammation in Alzheimer's disease. Biomark Med 4:27-36

31. Musiek ES, Brooks JD, Joo M, Brunoldi E, Porta A et al (2008) Electrophilic cyclopentenone neuroprostanes are antiinflammatory mediators formed from the peroxidation of the omega-3 polyunsaturated fatty acid docosahexaenoic acid. J Biol Chem 283:19927-19935

32. Roberts LJ, Fessel JP, Davies SS (2005) The biochemistry of the isoprostane, neuroprostane, and isofuran pathways of lipid peroxidation. Brain Pathol 15:143-148

33. Birkle DL, Bazan NG (1987) Effect of bicuculline-induced status epilepticus on prostaglandins and hydroxyeicosatetraenoic acids in rat brain subcellular fractions. J Neurochem 48:1768-1778

34. Bazan NG (2006) Cell survival matters: docosahexaenoic acid signaling, neuroprotection and photoreceptors. Trends Neurosci 29:263-271

35. Musto AE, Samii MS, Hayes JF (2009) Different phases of afterdischarge during rapid kindling procedure in mice. Epilepsy Res 85:199-205

36. Tu B, Bazan NG (2003) Hippocampal kindling epileptogenesis upregulates neuronal cyclooxygenase-2 expression in neocortex. Exp Neurol 179:167-175

37. Taha AY, Jeffrey MA, Taha NM, Bala S, Burnham WM (2010) Acute administration of docosahexaenoic acid increase resistance to pentylenetetrazol-induced seizure in rats. Epilepsy Behav 17:336-3343

38. Rundfeldt C, Hönack D, Löscher W (1990) Phenytoin potently increases the threshold for focal seizures in amygdala-kindled rats. Neuropharmacology 29:845-851

39. Berry CB, Hayes D, Murphy A, Wiessner M, Rauen T, McBean GJ (2005) Differential modulation of the glutamate transporters GLT1, GLAST and EAAC1 by docosahexaenoic acid. Brain Res 1037:123-133

40. Xiao Y, Li X (1999) Polyunsaturated fatty acids modify mouse hippocampal neuronal excitability during excitotoxic or convulsant stimulation. Brain Res 846:112-121

41. Søgaard R, Werge TM, Bertelsen C, Lundbye C, Madsen KL, Nielsen CH, Lundbaek JA (2006) GABA(A) receptor function is regulated by lipid bilayer elasticity. Biochemistry 45:13118-13129

42. Cole-Edwards KK, Musto AE, Bazan NG (2006) c-Jun N-terminal kinase activation responses induced by hippocampal kindling are mediated by reactive astrocytes. J Neurosci 26:8295-8304

43. Lehtimäki KA, Keränen T, Palmio J, Mäkinen R, Hurme M, Honkaniemi J, Peltola J (2007) Increased plasma levels of cytokines after seizures in localization-related epilepsy. Acta Neurol Scand 116:226-230

44. Vezzani A, Baram TZ (2007) New roles for interleukin-1 Beta in the mechanisms of epilepsy. Epilepsy Curr 7:45-50

45. Bazan NG (2008) Neurotrophins induce neuroprotective signaling in the retinal pigment epithelial cell by activating the synthesis of the anti-inflammatory and anti-apoptotic neuroprotectin D1. Adv Exp Med Biol 613:39-44 
46. Tamura Y, Simizu S, Osada H (2004) The phosphorylation status and anti-apoptotic activity of $\mathrm{Bcl}-2$ are regulated by ERK and protein phosphatase 2A on the mitochondria. FEBS Lett 569:249-255

47. Ruvolo PP, Deng X, Ito T, Carr BK, May WS (1999) Ceramide induces $\mathrm{Bcl} 2$ dephosphorylation via a mechanism involving mitochondrial PP2A. J Biol Chem 274:20296-20300

48. Chiang CW, Harris G, Ellig C, Masters SC, Subramanian R, Shenolikar S, Wadzinski BE, Yang E (2001) Protein phosphatase $2 \mathrm{~A}$ activates the proapoptotic function of BAD in interleukin-3dependent lymphoid cells by a mechanism requiring 14-3-3 dissociation. Blood 97:1289-1297

49. McCright B, Rivers AM, Audlin S, Virshup DM (1996) The B56 family of protein phosphatase 2A (PP2A) regulatory subunits encodes differentiation-induced phosphoproteins that target PP2A to both nucleus and cytoplasm. J Biol Chem 271:22081-22089

50. Deng X, Gao F, May WS (2009) Protein phosphatase 2A inactivates Bcl2's antiapoptotic function by dephosphorylation and up-regulation of Bcl2-p53 binding. Blood 113:422-428

51. Xin M, Deng X (2006) Protein phosphatase 2A enhances the proapoptotic function of Bax through dephosphorylation. J Biol Chem 281:18859-18867

52. Antony R, Lukiw WJ, Bazan NG (2010) Neuroprotectin D1 induces dephosphorylation of Bcl-xL in a PP2A-dependent manner during oxidative stress and promotes retinal pigment epithelial cell survival. J Biol Chem 285:18301-18308 